\title{
Study Site Accrual Status Code
}

National Cancer Institute

\section{Source}

National Cancer Institute. Study Site Accrual Status Code. NCI Thesaurus. Code C94139.

A coded value specifying the phase in the lifecycle of a participating site relative to the enrollment of additional subjects in the given study. 